with Füsun Türetken

\title{
Interiors of memories: A study of personal memories based on the works of Luigi Serafini and Georges Perec
}

This research project considered the use of personal memories of the house I grew up in as a narrative for the inception of drawn spaces. Inspired by the work of Italian illustrator Luigi Serafini's Codex Seraphinianus (1981) and French writer Georges Perec's Species of Spaces and Other Pieces (1997), memories were reconfigured as narratives, which then became benchmarks for the creation of images. Particular images themselves responded to the vibrant nature of the memory, but emphasised the spatial dynamic they suggested. The work aimed to create a series of fantastical spaces that themselves invoked a new set of paradigms. Focusing on the narrative space or tableau against which all characters and actions occur, this project sought to emphasize the role space plays in various stories, and investigated how narration might become the focal point of the architect's work.

\section{Features of the fantastic}

Despite numerous attempts to define fantasy as a genre, little consensus exists. More generally, fantasy is regarded as an "imaginative fiction dependent for effect on strangeness of setting (such as other worlds or times) and characters (such as supernatural beings)" (Fantasy, n.d.). In The Fantastic: A Structural Approach to a Literary Genre (1975), literary critic Tzvetan Todorov described the fantastic as a state in which a person is uncertain whether the events he/she is witnessing are real or imaginary: "The fantastic is that hesitation experienced by a person who knows only the laws of nature, confronting an apparently supernatural event" (25). In this light, fantasy allows the reader to experience a different order built on a present reality of the world, while calling that reality into question. In my own work, looking to the past for material with which to create imagined worlds similarly involved reworking the order of reality subsisting with them. Yet as recollections, they already carried within themselves a certain extension and bending of reality, an aspect that readily permitted the creation of fantastical narratives and spaces.

\section{Memory, space and the domestic}

French philosopher Gaston Bachelard outlined the relationship between memory and space in The Poetics of Space (1994). There he interpreted the domestic interior 
as a being psychically rich with every corner, door, and window readily combining actual and remembered experiences. As such memories are not just of the past but subsist with, and are housed by, domestic space itself (Bachelard, 1994: 3-7). He writes of his childhood home;

In the past, the attic may have seemed too small; it may have seemed cold in winter and hot in summer. Now, however, in memory recaptured through daydreams, it is hard to say through what syncretism the attic is at once small and large, warm and cool always comforting. (Bachelard, 1994: 10)

As Bachelard suggested, memories always extend and prolong space, radically colouring the very experience of it. While individuals may experience space divergently by Bachelard's account domestic spaces particularly gather memories of inhabiting or dwelling well, securely, happily.

\section{Codex Seraphinianus and Species of Spaces and Other Pieces}

Luigi Serafini's Codex Seraphinianus (1981) constituted a base for the graphical production of spaces undertaken for this project. The book is an encyclopedia made up of different chapters dealing with fauna, flora, creatures, and architecture. The drawn fantastic worlds represented in the codex shift between the real, the imagined, the lived, and the dreamt. Serafini owes many of his illustrations to his childhood memories, as Derek White (2012) has written. In his illustrations, Serafini extrapolates elements from his environment and manipulates them using various methods including grafting, repetition, scaling up/down, and distorting the shape or function of particular objects, strategies I similarly employed in my own project.

George Perec's Species of Spaces and Other Pieces (1997) was a critical source for the written narratives I assembled to accompany each image. Perec's episodes were infused with layers of personal memories of spaces and objects, allowing the reader to obtain a different perspective of the home. Perec uses the term "infra-ordinary" to capture a sense in which everyday life itself is composed of a complex array of strange, if minor, qualities that are far from ordinary when attended to (Perec, 1997: 206). For example, the space of the bedroom is more than merely a collection of objects; it is richly infused with affects and mnemonic qualities as Perec describes:

My memories are attached to the narrowness of that bed, to the narrowness of that room, to the lingering bitterness of the teas that was too strong and too cold...The resurrected space of the bedroom is enough to bring back to life, to recall, to revive memories, the most fleeting and anodyne along with the most essential. (21)

In this description, it is not just the object reality of the space that is given; he provides the reader with the tools to enter into and experience the space imaginatively via dreams and memories projected there ourselves. The importance of this book lies in Perec's capture of how space is in reality, investing commonplace objects within interiors with lived qualities, qualities rich in attachments that simultaneously collectivize and individualise. 


\section{Interiors of memories}

The works of Serafini and Perec relate to each other in their use of memory as a tool for the creation of narratives of attachment and engagement. Both authors manipulate specific objects and spaces in attempts to demonstrate the complex essence of space, elevating objects beyond the trivial and the mundane. In the process, both oeuvres redefine the existent typologies of space and object.

The episodes below, along with their images, create a set of fantastic spaces based on memories that question perceptions of the domestic. Each image digitally extends memory. Each strips away objective reality of the domestic to open a pathway into the infra-ordinary and the fantastical-domains never far from each other, or indeed from the real. As Paul Feyerabend beautifully put it: "We need a dream world in order to discover the features of the real world we think we inhabit "(1975: 22). 
The Guest Toilet

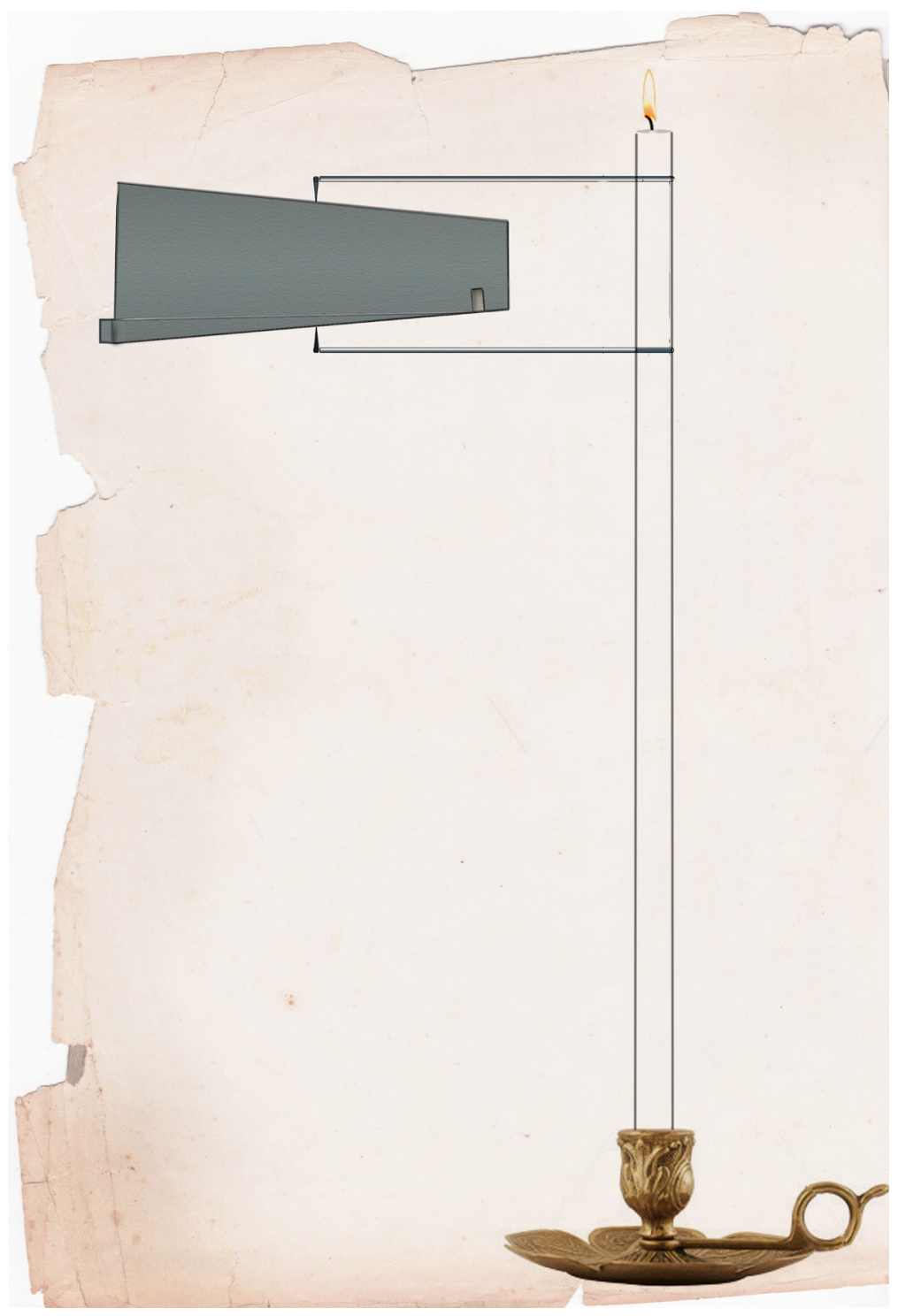

The guest toilet was tiny. No more than $2 x 2 s q m$.

It was our hiding place during the war.

Most of the façades of our house were made of glass therefore hiding in other rooms wasn't an option as

the danger of glass shattering during attacks was too risky. As soon, as we heard explosions, my sister and I

would clamber, climbing over furniture, dodging tables and random items strewn on the floor, destination:

the tiny toilet. It felt like passing through a land of mines before reaching the door. Once we crossed the

door into the toilet, we fell into complete darkness. We lost electricity during the raids. In this tiny space,

my older sister and I would be curled up together somewhere in the back. It was total darkness until mum

lit up a candle. I remember the flickering light of that candle hovering over our heads, casting dancing

shadows throughout the tiny space. When the raid was over, we would leave the toilet hesitantly. 
The Circulation \& Bomb Shelter

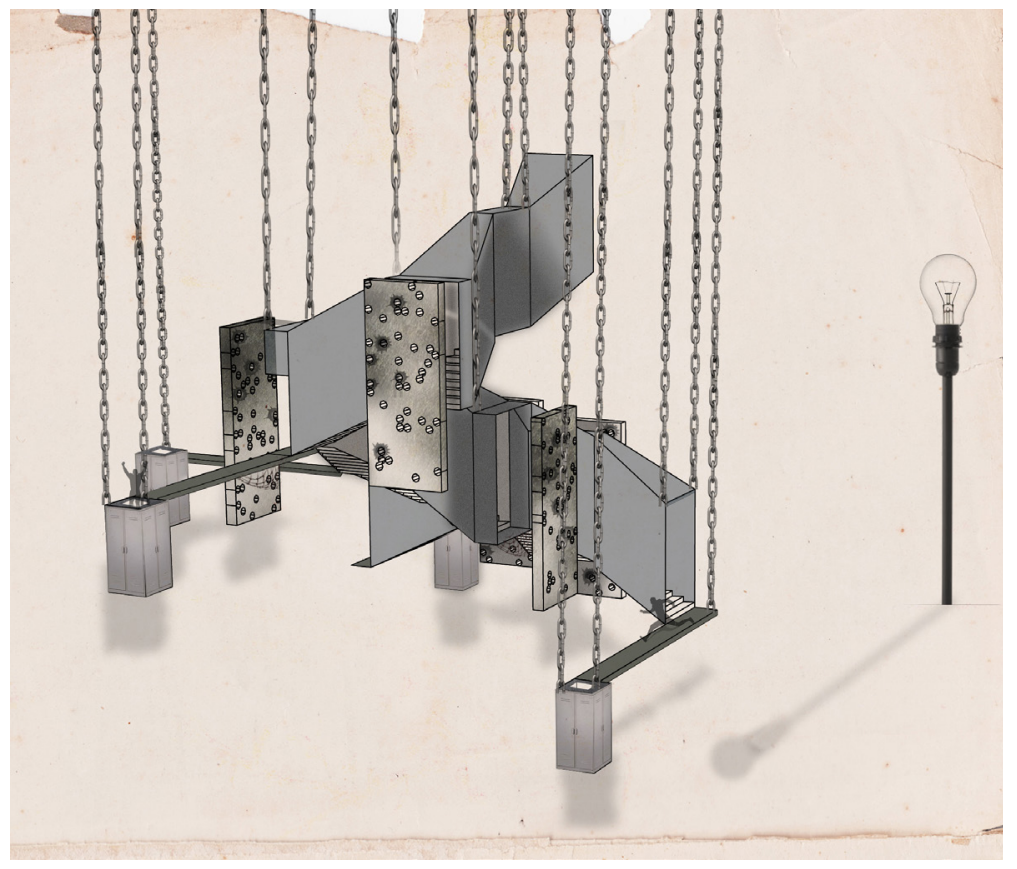

I have vague memories of that space.

I was pretty young when the civil war started.

I always felt like I was going down into a dungeon; maybe because the stairs leading there were always

dark. I remember the loud sounds as everyone rushed down the stairs: doors slamming shut, kids

screaming, neighbors calling out to each other, the sounds of shoes and flip-flops scurrying down the

staircase. I never quite understood what was happening. I was too young to understand.

I can still hear the muffled sounds of bombs exploding above us. Some wear louder than others. I could

hear the gasps of the people around me as the bombs exploded. The atmosphere felt cold, although

according to my parents, there were about 15 people squished into a $5 \times 4$ sqm. space.

Years later that space was even colder; the grey metal cupboards still lined the walls. The war had ended. 
The Bedroom
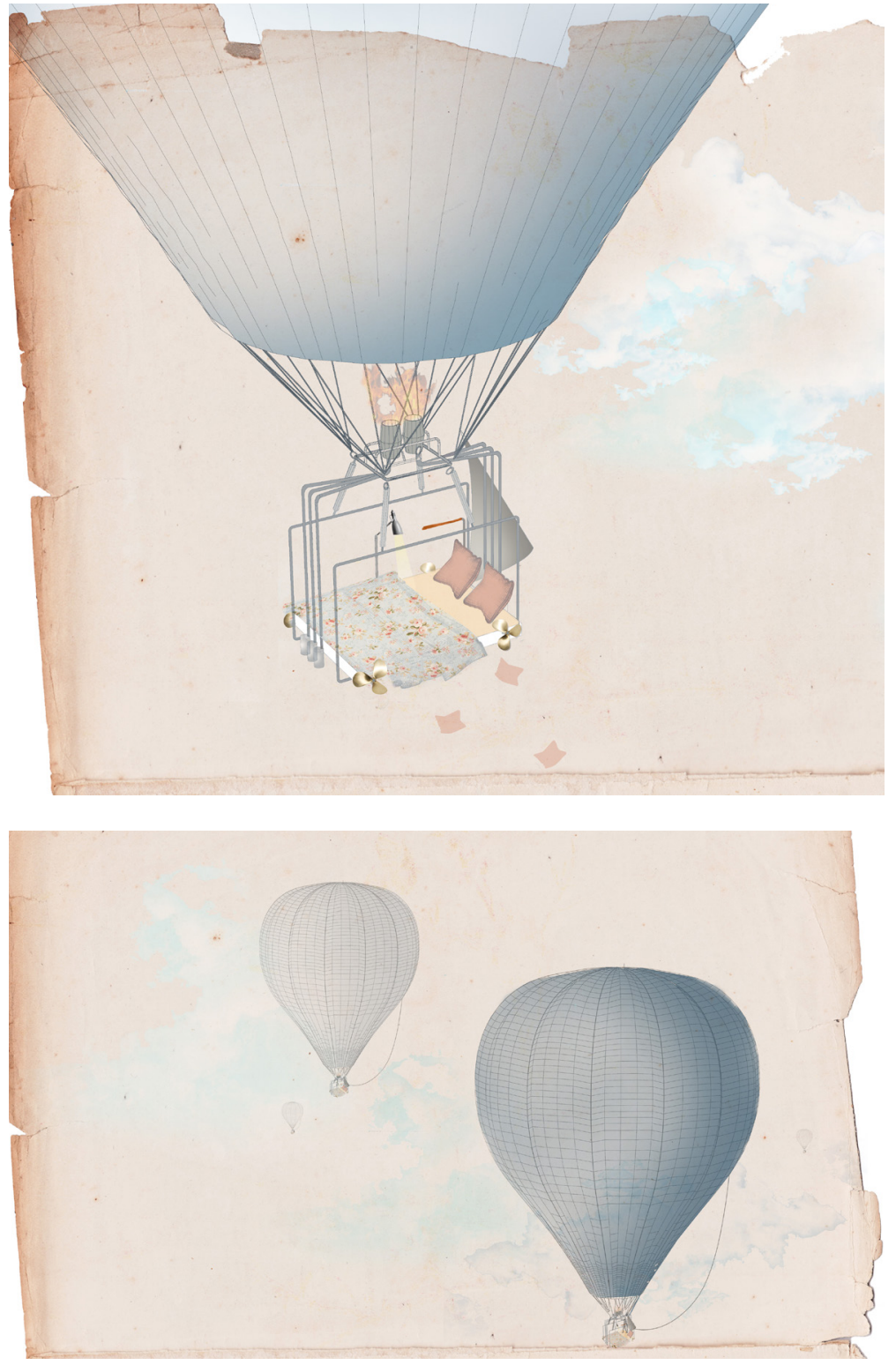

Fig. 3 Joanne Choueiri (2014).

"The bedroom"

Fig. 4 Joanne Choueiri (2014).

"The bedrooms"
My bedroom is quite small. When you enter, the bed is right in front of you. It takes up most of the room. It has no headboard.

It squeaks a lot.

We bought it from Ikea.

It squeaks a lot.

There's a window above my bed opening up the room to the outside world, making it seem a bit larger

than it actually is. You can see the neighboring building from it. On the ceiling above me are the pipes that

link to the radiator. It can get quite loud and disturbing. Right next to the pipes, right above my bed, hangs

a small hot air balloon a friend gave to me to remind me to dream more. To the left there is a grey cupboard

that was moved from my sister's room. After my dad passed away, the curtains stay up all the time. It was

in that same bed that I learned the bad news. The room became even smaller that night.

The curtains stay up all the time.

After that day, everything changed in this space. It became a space of solitude away from people...

away from the world...

It became my memories of a past. It became my lost dream of a future. It became a space of escape. 
The Entrance

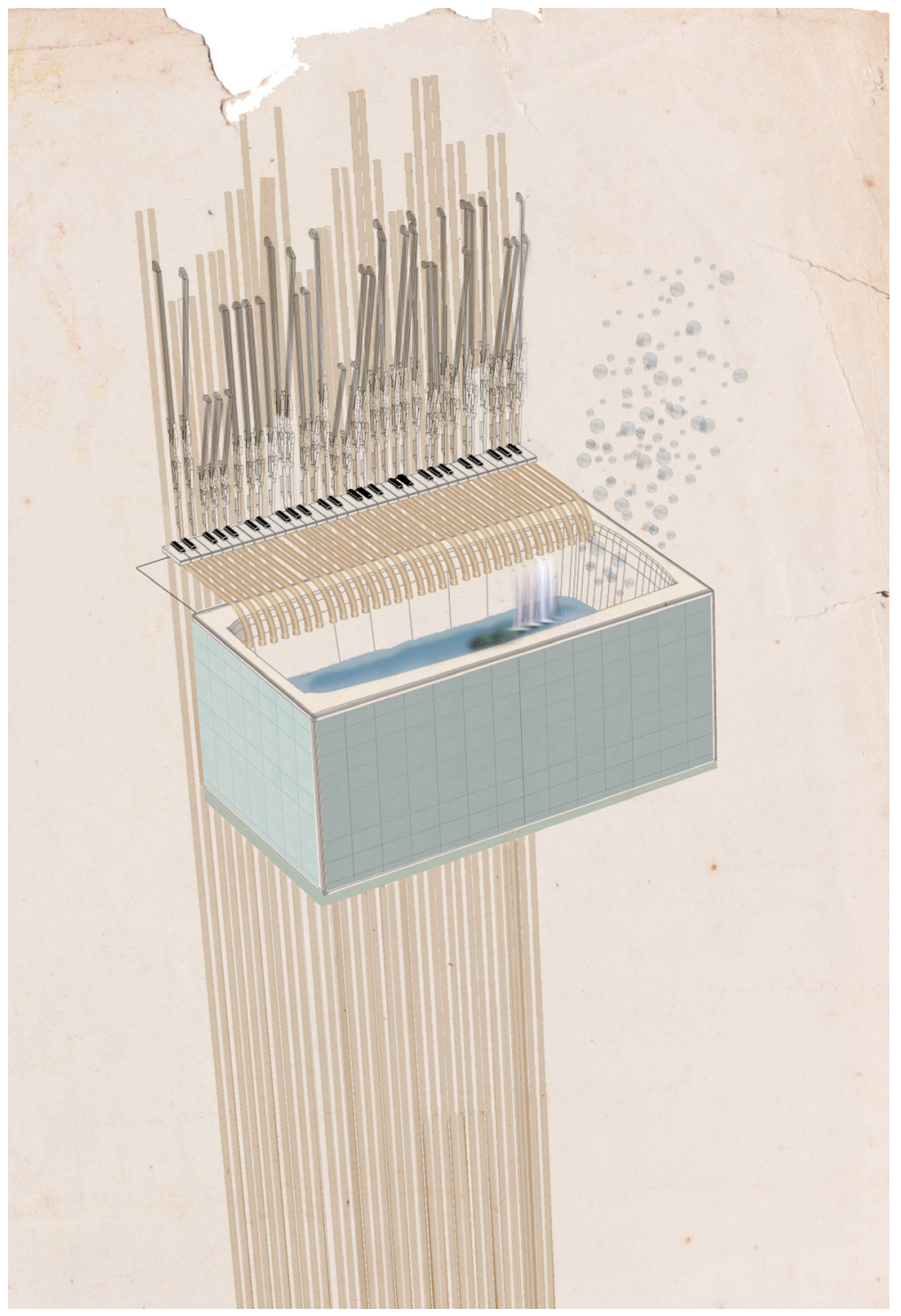

The entrance hall is the central place of the apartment. It was away from the glass facades, so it became a

secondary safe place. Weirdly enough, the entrance hall was also the place where we took quick showers

during the war. The bathrooms, having glass windows, were always too dangerous. My mother would lay out the bucket in the foyer and splash hot water, which was heated on the stove, rapidly before the next

attack. Years later, when the war had ended, a piano was added onto the entrance hall.

My sister and I played the piano while growing up. These endless lessons became a tedious job after a

while. We stopped playing in our teenage years right when other things became more important; since then

it was no longer the centerpiece of the entrance hall.

The piano now, lies on the side as a decorative two-level table where candles and vases are set out. 
The Kitchen

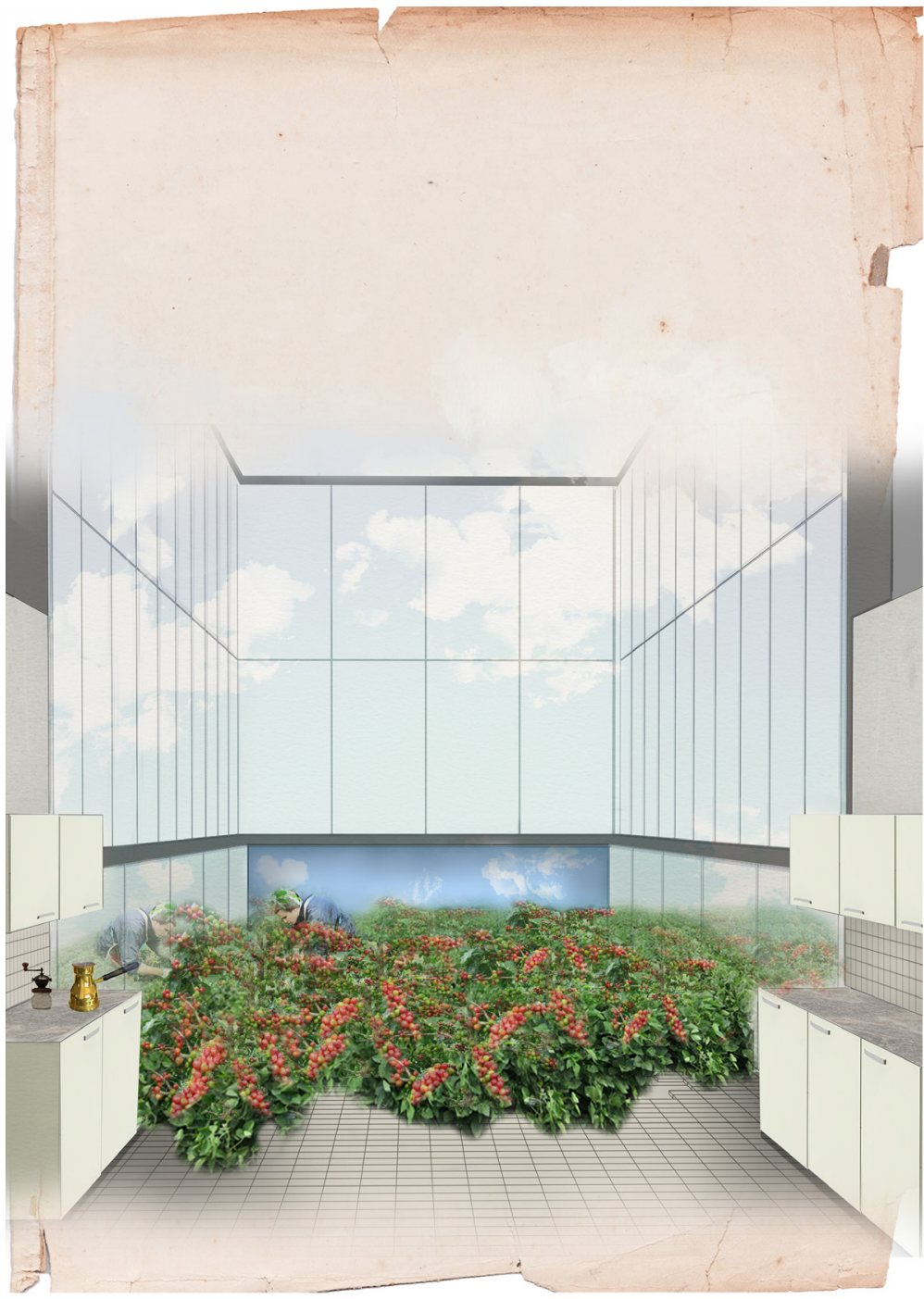

In the mornings, waking up to the smell of coffee slowly seeping out from the kitchen was one of my

preferred times of the day. The standard U-shaped kitchen was engulfed with an intense coffee aroma.

Coffee brought everyone together, the family, the neighbors, and the occasional visitors.

Our favorite brand of coffee was called Café Brazil, which led to the assumption that the beans were

actually imported from Brazil. So, I would always imagine being amidst an endless coffee field in Brazil.

Both my assumptions and imagination misled me, for as it turns out, the beans were not of Brazilian origin. 


\section{REFERENCES}

Bachelard, G. (1994). The poetics of space. (M. Jolas, Trans.).

Boston: Beacon Press.

Fantasy (n.d.). In MerriamWebster Online Dictionary. Retrieved from http://www. merriam-webster.com/dictionary/ narrative

Feyerabend, P. (1975). Against method: Outline of an anarchist theory of knowledge. London, England: New Left Books.

Griffith Winton, A. (2013).

Inhabited space: Critical theories and the domestic interior. In Weithal, L. \& Brooker, G. (Eds.). The Handbook of interior architecture and design (pp. 40-49). London, England \& New York, NY: Bloomsbury Press.

Marks, L. (2000). The skin of the film. Durham, NC: Duke University Press.

Mitchell, K. (2009). Growing up in wonderland: An analysis of Lacanian subject formation within the secondary worlds of children's fantasy (Unpublished project for a Bachelor of Arts, Honours degree). Jefferson City, TN: Carson-Newman University.

Mitchell, P. (2004). Constructing the architext: George Perec's Life a User's Manual. Mosaic: An Interdisciplinary Critical Journal, 37 (1), 1-16.

Perec, G. (1997). Species of spaces and other pieces. ( $\mathrm{J}$. Sturrock, Trans.). London, England: Penguin Books.

Serafini, L. (1981). Codex seraphinianus. Milano: Franco Maria Ricci.

Sullivan, C. (2001). Folklore and fantastic literature. Western folklore, 60(4), 279-296.

Todorov, T. (1975). The fantastic: A structural approach to a literary genre. (R. Howard, Trans.). Ithaca, NY: Cornell University Press.

White, D. (2012). Decoding the decodex: Demystifying Luigi Serafini's Codex Seraphinianus. Retrieved from http:// www.5cense.com/12/decoding decodex.htm 